\title{
ANATOMIA DA MADEIRA DE MELIA AZEDARACH L. (MELIACEAE) ${ }^{1}$
}

\author{
ANELISE MARTA SIEGLOCH ${ }^{2}$ SABRINA FINATO ${ }^{3}$ \\ PAULO FERNANDO DOS SANTOS MACHADO ${ }^{4}$ TALITA BALDIN $^{5}$ \\ DARCI ALBERTO GATTO ${ }^{6}$ JOSÉ NEWTON CARDOSO MARCHIORI $^{7}$
}

\section{RESUMO}

A anatomia da madeira de Melia azedarach L. é descrita de acordo com IAWA (1989) e ilustrada com fotomicrografias, com base em material procedente de Jaguari, RS, Brasil. Na estrutura da madeira destacamse: poros em múltiplos radiais; placas de perfuração simples; elementos vasculares pequenos; pontoações intervasculares pequenas, alternas e ornamentadas; parênquima axial vasicêntrico, confluente e marginal; raios homogêneos; e fibras libriformes não septadas.

Palavras-chave: Anatomia da madeira, Melia azedarach, Meliaceae.

\section{ABSTRACT}

[Wood anatomy of Melia azedarach L.].

The wood of Melia azedarach is anatomically described according to IAWA (1989) and illustrated with photomicrographs, based on material collected in the municipality of Jaguari, Rio Grande do Sul State, Brazil. The anatomical structure presents: radial multiples vessels; simple perforation plates; short vascular elements; small, alternate vestured pits; vasicentric, confluent and marginal axial parenchyma; homogeneous rays; and libriform non septate fibers.

Key words: Wood anatomy, Melia azedarach, Meliaceae.

\section{INTRODUÇÃO}

Melia azedarach, o popular cinamomo, pertence à família Meliaceae e recebe, ainda, os

1 Recebido para publicação em 11/08/2015 e aceito para publicação em 30/09/2015.

2 Doutoranda do Programa de Pós-Graduação em Engenharia Florestal. Bolsista - CAPES. Universidade Federal de Santa Maria. Santa Maria, RS, Brasil. anesiegloch@yahoo.com.br

3 Mestranda do Programa de Pós-Graduação em Engenharia Florestal. Bolsista - CNPq. Universidade Federal de Santa Maria. Santa Maria, RS, Brasil.

4 Mestrando do Programa de Pós-Graduação em Engenharia Florestal. Bolsista - CNPq. Universidade Federal de Santa Maria. Santa Maria, RS, Brasil.

5 Doutoranda do Programa de Pós-Graduação em Engenharia Florestal. Bolsista - CAPES. Universidade Federal de Santa Maria. Santa Maria, RS, Brasil.

6 Engenheiro Florestal, Dr. Bolsista de Produtividade em Pesquisa (CNPq - Brasil). Professor adjunto do Curso de Eng. Industrial Madeireira da Universidade Federal de Pelotas e professor do Programa de Pós-Graduação em Engenharia Florestal, Universidade Federal de Santa Maria. Santa Maria, RS, Brasil.

7 Engenheiro Florestal, Dr. Bolsista de Produtividade em Pesquisa (CNPq - Brasil). Professor Titular do Departamento de Ciências Florestais, Universidade Federal de Santa Maria. Santa Maria, RS, Brasil. nomes de santa-bárbara, jasmim-de-caiena, lilás-da-china, árvore-santa, loureiro-grego, cháde-soldado, lilás-de-soldado e orgulho-da-china. Originária da Índia e China, é árvore muito cultivada no Brasil e sub-espontânea nos estados de São Paulo ao Rio Grande do Sul (Lorenzi et al., 2003).

Árvore caducifólia, de 15 a 20 m de altura, apresenta tronco pardo-acinzentado ou marromavermelhado, com fissuras longitudinais e oblíquas, e copa aberta, com longas folhas alternas, bipinadas, com 3-6 pares de pinas secundárias opostas, cada uma com 4-5 pares de folíolos opostos, verde-escuros, ovalados ou elípticos, com margem parcial ou inteiramente denteada e ápice agudo. As flores, róseo-liláceas e muito perfumadas, aparecem de setembro a novembro, compondo inflorescências axilares ramificadas. Os frutos, do tipo drupa, são ovóide-arredondados e marrom-amarelados (Lorenzi et al., 2003).

Espécie ornamental e de boa sombra, é indicada para parques e arborização urbana (Lorenzi et al., 2003). Pece et al. (1996) a re- 
comendam para reflorestamentos, por sua boa adaptação edafo-climática, rápido crescimento e madeira de ótima qualidade para serraria, laminados e faqueados.

A madeira, de densidade baixa, grã direita e textura média, apresenta baixa durabilidade natural aos organismos xilófagos, sobretudo em contato com o solo; o cerne é moderadamente resistente à impregnação com produtos preservativos (Bobadilla, 2004). A madeira também não se recomenda para uso estrutural ou peças de grandes dimensões, devido à baixa resistência mecânica (Venson, 2003).

A respeito da estrutura microscópica da madeira, Metcalfe \& Chalk (1972) relacionam os seguintes caracteres para as Meliaceae: poros pequenos a médios, geralmente em múltiplos radiais de 2 a 3; placas de perfuração simples; elementos vasculares de comprimento médio; pontoações intervasculares tipicamente pequenas, ocasionalmente grandes; pontoações raiovasculares semelhantes às intervasculares; parênquima paratraqueal (vasicêntrico, aliforme ou confluente) e em faixas marginais, por vezes com células cristalíferas; parênquima apotraqueal em faixas regulares, em poucas espécies; raios heterogêneos, embora homogêneos em alguns gêneros; raios unisseriados, com 2-4 células de largura, por vezes com mais de 9 células de largura e estratificados; fibras libriformes, de comprimento curto a médio, septadas na maioria das espécies; e canais intercelulares ou traumáticos esporádicos.

Para o gênero Melia, os mesmos autores mencionam: poros em cachos, em anéis porosos ou semi-porosos, espessamentos espiralados; cristais em câmaras; raios homogêneos, com a 79 células de largura (em algumas espécies); fibras não septadas; e ocorrência ocasional de canais intercelulares traumáticos.

O presente estudo, ao descrever o lenho de Melia azedarach, visa a analisar sua estrutura anatômica, distinguindo-a das Meliaceae nativas na flora regional.

\section{MATERIAL E MÉTODOS}

O material em estudo consiste do lenho de três indivíduos, coletados no município de Jaguari, Rio Grande do Sul (Brasil).

Para a confecção de lâminas histológicas foram extraídos 3 corpos de prova ( 3 × 3 x $3 \mathrm{~cm}$ ) de cada indivíduo, orientados para obtenção de cortes nos planos transversal (X), longitudinal radial (R) e longitudinal tangencial (T); um quarto bloquinho foi também separado, com vistas à maceração.

O preparo de lâminas histológicas seguiu a metodologia descrita em Burger \& Richter (1991). A maceração foi realizada pelo método Ácido-nítrico-acético (Barrichelo et al., 1983). Os cortes anatômicos foram tingidos com safranina (1\%) e azul-de-astra; o macerado apenas com safranina (1\%). A montagem de lâminas permanentes foi feita com Entellan.

A descrição microscópica baseou-se nas recomendações do IAWA Committee (Wheeler et al., 1989). No caso da percentagem dos tecidos, foram realizadas 600 determinações ao acaso, com auxílio de contador de laboratório, conforme proposto por Marchiori (1980). A abundância de poros foi obtida a partir de um quadrado de área conhecida, superposto a fotomicrografias de seções transversais da madeira.

As medições foram realizadas em microscópio Carl Zeiss, no Laboratório de Anatomia da Madeira da Universidade Federal de Santa Maria. Nas características quantitativas, os números entre parênteses equivalem aos valores mínimos e máximos observados; o valor que acompanha a média é o desvio padrão. As fotomicrografias foram tomadas em microscópio Leica DM 1000, equipado com câmera digital Olympus Camedia CX-40, no Laboratório de Anatomia da Madeira do Centro de Educação Superior Norte do Rio Grande do Sul (CESNORS-UFSM), campus de Frederico Westphalen, RS. 


\section{DESCRIÇÃO ANATÔMICA}

Anéis de crescimento: distintos; delimitados por poros de maior diâmetro no início do anel e parênquima marginal (Figura 1A,B).

Vasos: escassos $\left(6 \pm 0,8(5-8) / \mathrm{mm}^{2}\right)$, ocupando $24 \pm 2,6 \%$ do volume da madeira. Porosidade em anel. Poros em múltiplos radiais de 2-12 (47\%), solitários (39\%) ou em múltiplos racemiformes (14\%); em arranjo radial, no lenho inicial, e dentrítico, no lenho tardio. Poros circulares ou ovais $(266 \pm 89(63-400) \mu \mathrm{m})$ e de paredes espessas $10 \pm 3,1$ (6-16) $\mu \mathrm{m}$ (Figura 1A,B). Elementos vasculares curtos $208 \pm 37$ (130-300) $\mu \mathrm{m}$, com placas de perfuração simples, oblíquas ou transversais ao vaso. Apêndices curtos $(27,8 \pm 14(10-50) \mu \mathrm{m})$, ou ausentes. Pontoações intervasculares pequenas e ornamentadas, de 6,8 $\pm 0,9(5,2-8,2) \mu \mathrm{m}$, alternas, circulares, por vezes poligonais, com abertura em fenda inclusa, frequentemente coalescente (Figura 1D). Pontoações raio-vasculares, semelhantes às intervasculares, embora menores $(5,8$ $\pm 0,5(5,2-6,7) \mu \mathrm{m})$. Espessamentos espiralados, ausentes. Conteúdo, presente.

Parênquima axial: ocupando $12 \pm 5 \%$ do volume da madeira; em arranjo vasicêntrico, confluente, e em faixas marginais. Conteúdo, presente (Figura 1A,B). Séries parenquimáticas de 4-14 células e $418 \pm 65(313-550) \mu \mathrm{m}$ de altura (Figura 1F). Cristais romboédricos, presentes.

Raios: pouco numerosos $4 \pm 0,5$ (3-4) raios/ $\mathrm{mm}$, representando $18 \pm 4,9 \%$ do volume da madeira. Tecido radial homogêneo, composto inteiramente de células procumbentes (Figura 1E,F). Raios multisseriados com 2-7 células de largura e $297 \pm 80$ (113-450) $\mu \mathrm{m}$ de altura, com 6-23 células. Conteúdo, presente. Raios agregados, presentes. Raios fusionados, células envolventes, células radiais de paredes disjuntas e células perfuradas, ausentes. Cristais, ausentes.

Fibras: libriformes, de comprimento médio (1286 $\pm 180(980-1600) \mu \mathrm{m})$, com $15 \pm 3$ (9-
20) $\mu \mathrm{m}$ de largura, e paredes finas a espessas $3,3 \pm 0,7(1,9-4,4) \mu \mathrm{m}$, ocupando $46 \pm 5,5 \%$ do volume da madeira (Figura 1D,F). Fibras gelatinosas, espessamentos espiralados, fibras septadas e traqueídeos, ausentes.

Outros caracteres: variantes cambiais, tubos laticíferos e taniníferos, canais intercelulares, células oleíferas, células mucilaginosas, estratificação, máculas medulares e cristais, ausentes.

\section{ANÁLISE DA ESTRUTURA ANATÔMICA}

A estrutura microscópica de Melia azedarach corresponde, em linhas gerais, ao referido por Metcalfe \& Chalk (1972) para a família Meliaceae e gênero Melia: porosidade em anel ou semi-difusa; poros em múltiplos radiais; placas de perfuração simples; parênquima paratraqueal vasicêntrico, confluente e marginal; pontoações intervasculares pequenas; pontoações raio-vasculares semelhantes às intervasculares; raios com 2-7 células de largura; tecido radial homogêneo; e fibras não septadas, de comprimento médio.

Os poros, de diâmetro pequeno a grande (63$400 \mu \mathrm{m})$, são maiores do que o citado por Metcalfe \& Chalk (1972) para Meliaceae; o comprimento dos elementos vasculares, ao contrário, é menor do que o registrado pelos mesmos autores para a família.

Em Melia azedarach, cabe salientar a não ocorrência de espessamentos espiralados e de canais traumáticos, como salientado, aliás, por Metcalfe \& Chalk (1972) para o gênero em questão.

Em comparação com Cabralea canjerana (Vell.) Mart., Cedrela fissilis Vell., Guarea macrophylla Vahn e Trichilia claussenii C. DC., espécies nativas no Rio Grande do Sul, a madeira de Melia azedarach pode ser distinguida por ter porosidade em anel, fibras libriformes não septadas e raios homogêneos, com 2-7 células de largura (Quadro 1). 


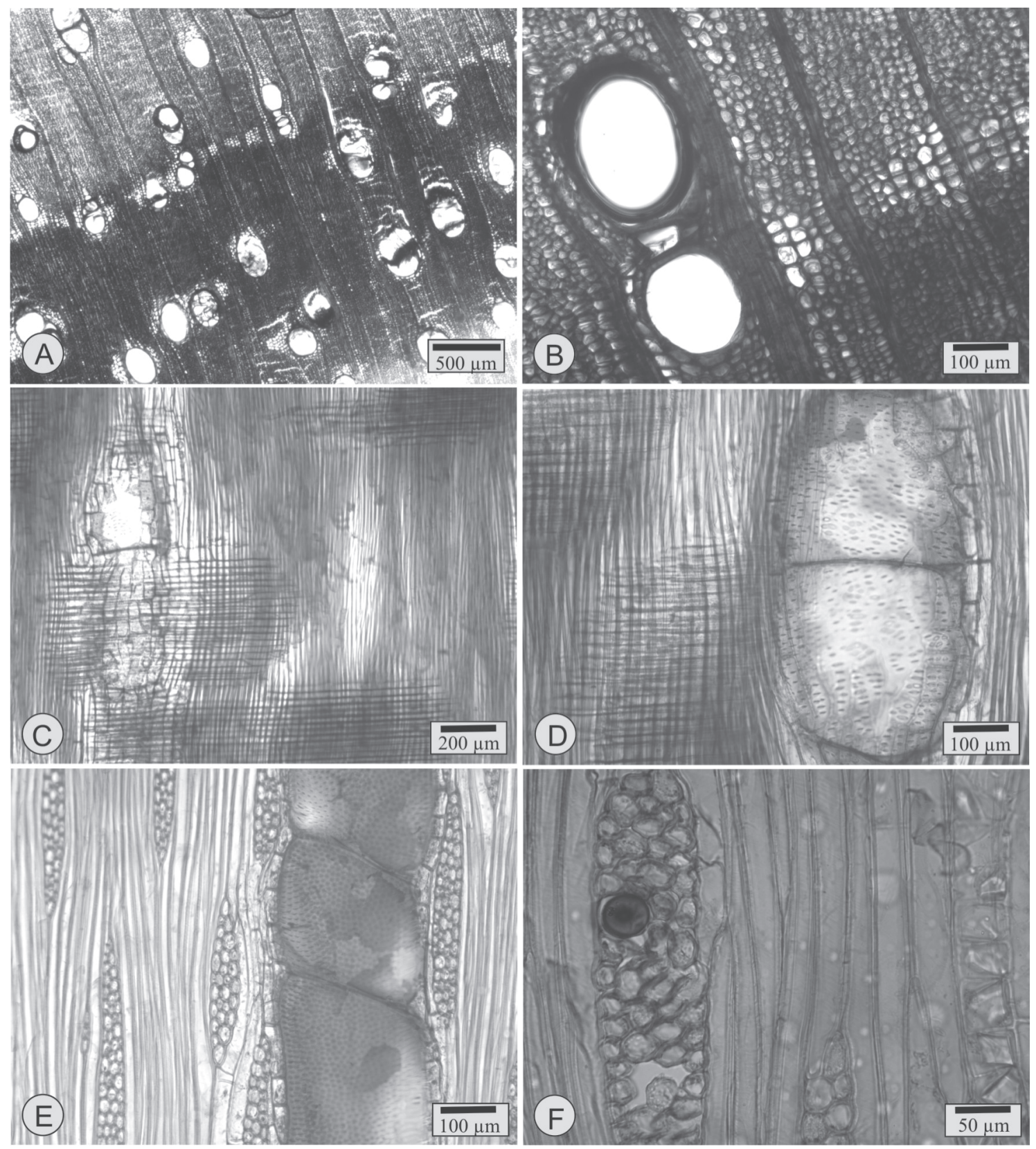

FIGURA 1 - Fotomicrografias da madeira de Melia azedarach. A - Seção transversal, mostrando porosidade em anel, limite de anel de crescimento marcado por poros de maior diâmetro no lenho inicial e parênquima marginal. B - Mesma seção, salientando um limite do anel de crescimento. C - Raios homogêneos, em seção radial, compostos inteiramente de células procumbentes. D - Elementos vasculares com pontoações pequenas e placas de perfuração transversais ao vaso (seção radial). E - Raios multisseriados, em seção tangencial. F - Raios multisseriados e parênquima axial (seção tangencial). 
Quadro 1 - Principais diferenças anatômicas entre Melia azedarach e espécies nativas de Meliaceae no sul do Brasil.

\begin{tabular}{|l|l|l|l|}
\hline \multicolumn{1}{|c|}{ Espécies } & Porosidade & \multicolumn{1}{c|}{ Fibras } & \multicolumn{1}{c|}{ Raios } \\
\hline Cabralea canjerana & difusa & libriformes septadas & heterogêneos, unisseriados e escassos bi e trisseriados \\
Cedrela fissilis & semi-difusa libriformes não septadas & heterogêneos, bi a tretrasseriados \\
Guarea macrophylla & difusa & libriformes septadas & heterogêneos, unisseriados e escassos bisseriados \\
Melia azedarach & em anel & libriformes não septadas & homogêneos, com 2-7 células de largura \\
Trichilia claussenii & difusa & fibrotraqueídeos não septados & heterogêneos, unisseriados e escassos bisseriados \\
\hline
\end{tabular}

\section{REFERÊNCIAS BIBLIOGRÁFICAS}

BARRICHELO, L.E.G.; FOELKEL, C.E.B. Processo nítrico-acético para maceração de madeira. Silvicultura, n. 28, p. 732-733, 1983.

BURGER, L.M.; RICHTER, H.G. Anatomia da Madeira. São Paulo: Ed. Nobel, 1991. 154 p.

BOBADILLA, E. A. Durabilidad natural de la madera de cinco espécies aptas para la industria de la construcción. 118 f. (Maestria em Tecnologia de Madera, Celulosa y Papel), Universidad Nacional de Misiones, Misiones, 2004.

LORENZI, H.; SOUZA, H.M. de; TORRES, M.A.V; BACHER, L.B. Árvores exóticas no Brasil: madeireiras, ornamentais e aromáticas. Nova Odessa: Instituto Plantarum, 2003, p.234.

MARCHIORI, J.N.C. Estudo anatômico do xilema secundário e da casca de algumas espécies dos gêneros Acacia e Mimosa, nativas no Estado do Rio Grande do Sul. Curitiba: UFPR, 1980. 186 f. Dissertação de Mestrado (Curso de PósGraduação em Engenharia Florestal).

METCALFE, C.R.; CHALK, L. Anatomy of the Dicotyledons. Oxford: Clarendon Press, 1972. p. 349-358.

PECE, M. et al., Crescimiento de una plantación de paraiso gigante (Melia azedarach var gigantea) de ocho años de edad en el departamento Alberdi en la província de Santiago del Estero. Quebracho, n. 4, p. 20-26, 1996.

WHEELER, E.A.; BAAS, P.; GASSON, P.E. IAWA list of microscopic features for hardwood identification. IAWA Bulletin, v.10, n. 3, 1989, p. 218-359.

VENSON, I. Estudio de las propiedades de la madera de Melia azedarach Linn. $119 \mathrm{f}$. Maestria (Maestro en Ciencia de Productos Forestales), Universidad de Guadalajara, 2003. 